\title{
MULTI-DISCIPLINARY SOCIO-TECHNICAL MANAGEMENT: INTEGRATING ROBOT TECHNOLOGY AND MANAGEMENT ISSUES
}

\author{
Kristian Wasén \\ Department of Business Administration \\ School of Economics and Commercial Law, Göteborg University \\ Box 600, SE-405 30 Göteborg, Sweden \\ e-mail kristian.wasen@mgmt.gu.se
}

\begin{abstract}
Optimal integrated design is potentially the most significant consequence of recent advances in service robotic technologies, enabling novel organizational forms to evolve. This paper provides a broad vision of the advent of a novel multi-disciplinary organizational function in the manufacturing and service sectors. Socio-technical management means an appreciation of the interplay among technology, economic issues and human factors. This allows an extended range of economic feasibility for robotic applications that also enables a more humane work organization. Contemporary trends are reviewed. Anticipated changes in operation and work organization are discussed, indicating a new robotic era.
\end{abstract}

Keywords: robotics, technological management, industrial engineering, automation and socio-economic issues, work and organizational design, organizational effectiveness

\section{INTRODUCTION}

The accelerating technical development of intelligent self-regulating robotic systems poses new challenges. Anyone who plans to work and live in the world of tomorrow needs to pay attention to how the situation might change and what the implication of these changes might be. The transformation that we are able to witness today will hopefully change our society for the better:

The processes that shape our technologies go right to the heart of the way in which we live and organize societies. Understanding these processes might help us to create different or better technologies ... It shapes our conduct at work and at home. It affects our health, the ways in which we consume, how we interact, and the methods by which we exercise control over others. [1]

The entry into the robotic era, with automated intelligent systems will play a decisive role in the transformation of management during the years and decades ahead. From this vantage point the missing element becomes evident; multifarious knowledge of complex socio-technical systems will be needed for optimal operation. This involves a much higher level of complexity of coordination and control in order to make the interlinked and often vulnerable systems more functional. Hence, this kind of management involves the interplay between many different knowledge areas and will accordingly require more extensive skills as well as a deeper understanding of systemic aspects.

Recent breakthroughs in service robotic technologies have gradually enabled more sophisticated forms of interaction between humans and robots. Robots are designed to interact with people in different contexts and environments. Earlier types of industrial robots have basically been dependent on relatively primitive interaction techniques, such as hand-controller, buttons, and graphical interfaces. Modern interactive robots enable more sophisticated interaction, such as communication with higher-level commands, including voice and gesture recognition. [2, 3, 4]

Changes in technology entail changes in values and norms, work roles, and social structures that profoundly alter an organization. Robotic systems are deployed to perform heavy, dirty, dull and repetitive tasks autonomously in order to relieve the strain on humans. Possibly, in our future daily world more advanced types of service robots will be conceived as work partners [3]. This transformation from lifeless artifacts to cooperative, interactive, and mobile partners (functioning as team members) enables new forms of synergies with humans. 
Sophisticated automated robotic systems however, will not be enough to ensure corporate survival. We must not forget the socio-technical and economical dimensions which are crucial for the adaptive and innovative performance in business. Robotic technology is a resource created for human purposes that must serve human, organizational and economical objectives.

In today's business, decision-making is complex and demanding. The survival of the manufacturing firm is hazardous in a complex world increasingly variable, unpredictable, and fraught with fatal risks. Therefore, its mobilization of multifarious competencies is becoming crucial. However, this complexity requires a holistic understanding (i.e. a general understanding of the total system, that is, a rough knowledge of its parts and how they interact) in order that management can make sound decisions and bridge communication gaps. For this very reason, the sociotechnical aspect is fundamentally important for business enterprises. This paper addresses concepts of human intelligence, economical objectives, and automated robotic technologies which working together and optimized will enable novel organizational forms to develop.

\section{THE ORIGINS OF MANAGEMENT}

The origins of modern management can be traced back thousands of years [5]. However, the organized development of management theory is commonly considered from the nineteenth century with the emergence of large industrial organizations, and consequent problems associated with their working conditions. 'Management' has been used as a concept of divide and conquer. It has also perennially sought its leadership models from the military organization, regarding business as a battlefield and stressing the organization of formal hierarchical relationships.

However, it is useful to recall that the practice of management and its relationship to military organization has far more historical antecedents. Pioneering organizational theorists and management thinkers, such as Frederick Taylor and Henry Fayol, were widely acknowledged in Europe and Japan at the time of the "machine age", while receiving only moderate recognition in their home countries $[6,7]$. All the leading thinkers were at that time vigorously involved in the improvement of management as a means of increasing industrial productivity, a perennial theme of management.

\subsection{Management as a science}

The father of modern forms of scientific management, Frederick Winslow Taylor (1875-1917), an American inventor and engineer published his concepts in one of his most well known publications entitled "The principles of scientific management” [6]. In Taylor's philosophy, management is based to a large extent on a number of practical guidelines. In particular, management gives detailed instructions to employees what tasks to perform. In this sense, management is imposed upon people, rather then together with people. Taylor's philosophy based on meticulous observations and methodological analysis of the best way how a specific task could be undertaken and completed. A large amount of industrial operations and body movements were accurately studied and registered that enabled analysis of every aspect of the work process. Having found the optimal procedure, employees then were instructed to apply it in a mechanical manner.

To fully understand Taylor's philosophy it must be placed in its rightful context. He lived and worked when mass production techniques, mechanization and industrialization were initially evolving. Taylor's ideas have largely been discarded and disparaged in modern management. Nevertheless, it is possible to notice Taylor's influence on the re-engineering movement, associated with breaking down business processes into constituents.

\subsection{The socio-technical systems paradigm}

The principal notion of traditional socio-technical theory is the concept of "boundary management", which implies a high degree of self-regulation throughout the organizational system [8, 10, 19]. Flexibility and adaptability is obtained through a general repertoire of complementary human skills, possessed by semi-autonomous groups. However, the idea of separate approaches to the social and the technical systems of an organization could no longer be sufficient. The proper technology is the one that best fits the total circumstances [9]. Studies of mechanization and automation "... disclosed a basic change in the core shop-floor tasks: the worker was outside the technology, adjusting, interpreting, monitoring, etc: he had become a manager of a work system: he needed conceptual and perceptual skills rather than manipulative and physical skills - to keep a complex system in a steady state” [10].

Nadel, classified institutions into regulative or operative. The former approach treats organizations exclusively as social systems, stressing cultural values and norms. The latter deals with material resources as organizational outputs [11]. Soon after Emery adapted Nadel's distinction, restricting the term 'socio-technical' to the operative institution [9]. The distinctive characteristic of such an operative organization is a wide-ranging interface that "consists of the relations between a non-human system and a human system” [10]. 
Previous investigations suggested that technology might influence managerial functions. Woodward's study [13] suggested that technology determines the organizational design. Fewer supervisors were found in continuous process than in mass production industries. It was suggested that the highest level of technological complexity occurs when a continuous process industry is mechanized and demands sophisticated feedback in the form of adaptive systems.

Von Bertalanffy's classic paper on "Open Systems in Physics and Biology" [12] became a source of influence at the time when the socio-technical movement began to evolve. Conceptually, it entailed a new view on how organizations were envisaged. By means of adopting the notion and metaphor of "open systems” organizations like organisms and machines needed to uphold a steady state (homeostasis).

\section{MODERN MANAGEMENT IN TRANSFORMATION}

\subsection{From mechanization to automation}

In today's industrial and service organizations we are able to witness an increasing automation, which is a natural extension of the previous mechanization. Automation of machines concerns replacement of human's sensory organs and intellectual abilities by these machines $[14,15,17,18]$.

In automated machines, the human function is to monitor the process and detect malfunctions. Hence, it is merely supervising the construction processes and detecting deviations that need to be corrected. This has increased effectiveness and productivity in operations. Improved operation productivity, interpreted in the broadest sense, has become a survival issue for many organizations. Therefore, socio-technical management must acquire multidisciplinary knowledge in order to be able to realize objectives of effective operations. Socio-technical management means an appreciation of the interplay of technology, business and human factors.

\subsection{From functional specialization to universalism}

In the machine age a leader was a professional, who considered organizations as closed systems. Such a single specialization model has dominated business thinking since the turn of the twentieth century. This paper, in contrast, does not assert single specialty but rather a multi-disciplinary management function. In the period of accelerated development of sophisticated technology, paradoxically, leadership competencies like corporate social responsibility and ethics will become increasingly decisive for the overall result and survival of the corporation.

\section{MULTI-DISCIPLINARY MANAGEMENT SKILLS IN THE ROBOTIC ERA}

\subsection{Social skills}

There will be a need for totally new integrated competencies for leading simultaneously both human and technological systems since these systems are becoming more complex in their interactivity. Managers with good social skills are able to get the best out of their people. Development of new work forms in the robotic era must consider human needs of meaningfulness, purpose and engagement for the optimization of performance of the combined system. Psychosocial considerations and initiatives to humane working environments in the service sector address the associated risk of social isolation.

\subsection{Technological skills}

Technical competence involves the knowledge and collection of behaviors that one can bring to productive completion of tasks. Technology cannot be separated from its social inputs. It must be integrated into business contexts that make full use of the knowledge, originality, and ingenuity of the human resources available. Hence, the highperformance construction worksite is a design that brings together technical, social, and economical subsystems in a manner that optimizes the correlation among them in order to produce effective operations. Robot systems will execute some of the work. According to Engelhardt and Edwards "The division of labor between the intelligent human and the smart system can be examined and optimized. In this way both the human and the machine can perform the portions of the task which each does best." [16]

\subsection{Economic and managerial skills}

Management, on the other hand mainly involves the knowledge of efficiency, planning, regulation, control, and stability. When effectively acquired and integrated, these social and managerial competencies will jointly establish a high-performance holistic organization. The concept of socio-technical management also implies important elements of decentralization, information transfer, steering, and control. Significant improvements of productivity can be achieved if the work is carried out without space and time limitations, for example, teleoperation of robotic systems in a virtual environment.

The traditional service sector approached the organization exclusively as a social system and management as the act of governing social processes. The robotic service systems, currently under development will however offer many different services in the future reflecting the change from the industrial to the service society. 


\section{CONCLUSION}

Intelligent technologies, such as novel and innovative robotic systems will make the high-performance operations of manufacturing and service business a fundamental driving force in the twenty-first century. A major concern in the present state of development is the replacement of the traditional functional specialization model that has dominated business thinking since the turn of the twentieth century. This paper, in contrast, does not assert single specialty but rather a multi-disciplinary management.

During the previous era, Frederick W. Taylor developed principles of scientific management. A philosophy of specialization that progressed into the field of industrial engineering and also laid the groundwork of organizational theory. These principles served business well for several decades but today's situation calls for other thoughts. The restrictions become even more evident in light of sophisticated automated robotic applications.

There are various implications of this paper for practicing managers and engineers. Managers need to take more cognizance of the interaction of economic, socio-political and technical aspects. There is a need for new holistic multi-disciplinary management education to raise the awareness of this situation. Therefore, managers could more readily understand and live with the uncertainty and ambiguity that is now so prevalent in modern management operation.

Thus, a novel multi-disciplinary business function that integrates both human intelligence, economic objectives and automated robot technology becomes increasingly important in the robotic era. In-depth grasp of the underlying foundations of these three elements of socio-technical management, and a vivid commitment to sustain them, are fundamental for optimization of automated robotic technologies. Therefore, the relation among these three factors should be the object of attention in future research. I contend that the multi-disciplinary socio-technical management function is indeed a concept that is essential for economic growth, competitiveness, increased efficiency and operational productivity in a global world.

\section{REFERENCES}

[1] Bijker, W. \& Law, J (eds.) Shaping Technology Building Society. London: MIT Press, 1992.

[2] Fong, T. Collaborative control: a robot-centric model for vehicle teleoperation, Ph.D. Thesis, Carnegie Mellon University, 2001.
[3] Halme, A., Salmi S., Leppänen I. and Ylönen S. "WorkPartner: Interactive Human-like Service Robot for Outdoor Applications”, The International Journal of Robotics Research, Vol. 22, pp. 627-640, 2003.

[4] Schraft, R. D. and Schmierer, G. Service Robots: Products, Scenarios, and Visions. Natic: Peters, 2000.

[5] Wren, D. The Evolution of Management Thought. New York: John Wiley \& Sons, 1994.

[6] Taylor, F.W. Principles of Scientific Management. New York: Harper, 1911.

[7] Fayol, H. Industrial and General Administration. Paris: Dunod, 1916.

[8] Emery, F.E. The Emergence of a New Paradigm of Work, Canberra: A.N.U, 1978.

[9] Emery. F.E. 'Characteristics of Socio-Technical Systems'. London: Tavistock Documents \#527. Abridged in F.E. Emery. The Emergence of a New Paradigm of Work. Canberra: Center for Continuing Education, 1959.

[10] Trist, E. L. The Evolution of Socio-technical Systems: A Conceptual Framework and an Action Research Program. Ontario Quality on Working Life Center, Issues in the Quality of Working Life Occasional paper, No.2, June 1981.

[11] Nadel, S.F. The Foundation of Social Anthropology. London: Cohen \& West, 1951.

[12] Von Bertalanffy. L. 'The Theory of Open Systems in Physics and Biology’. Science, Vol. 3, pp. 23-29, 1959.

[13] Woodward, J. Industrial Organization: Theory and Practice. London: Oxford University Press, 1965.

[14] Veillette, P. "The rise of the concept of automation" in (eds.) Howard Jacobson \& Joseph Roucek Automation and Society, New York, Philosophical Library, 1959.

[15] Zuboff, S. In the Age of the Smart Machine: The Future of Work and Power. NY: Basic Books, 1988.

[16] Engelhardt, K. G. \& Edwards, R. A. "Humanrobot integration for service robotics” in (eds.) M. Rahimi and W. Karowski Human Robot Interaction, London: Taylor \& Francis, p. 324, 1992.

[17] Miller, R K. Industrial robot handbook. Lilburn: The Fairmat press, 1987.

[18] McLoughlin, I \& Clark, J. Technological change at work. Milton Keynes: Open University Press, 1988. 